\title{
Influence of Different Heat Treatments on the Solid Particle Erosion Behavior of Aluminum Alloy AA 7075 in Industrial Applications
}

\author{
S. Karabay, M. S. BAYRAKLilar, E. BALCI* \\ University of Kocaeli Faculty of Engineering Department of Mechanical Engineering 41380 Kocaeli, Turkey \\ In this study, the solid particle erosion behavior of solutionized, artificially aged (T6) and annealed aluminum \\ alloy AA7075 has been investigated. The samples were eroded in solid particle erosion test equipment at $45^{\circ}$ \\ impingement angle and $75 \mathrm{~m} / \mathrm{s}$ impingement velocity with 180 mesh garnet erodent particles. Afterwards, mi- \\ crostructures of solutionized, artificially aged and annealed samples of AA7075 alloy were analyzed. In order to \\ figure out the effect of ductility on erosion rates, the Brinell hardness of the samples was measured. The sur- \\ face morphology images of the samples were taken before and after the erosion test by using scanning electron \\ microscope (SEM). The effects of the microstructures and the hardness on the erosion behavior of the different \\ heat treated specimens were examined. Finally, SEM images of the samples were deeply analyzed and the erosion \\ mechanisms which occurred on the surfaces of the samples were discussed.
}

DOI: $10.12693 /$ APhysPolA.127.1052

PACS: 81.05.Bx; 81.40.Cd; 81.40.Ef

\section{Introduction}

AA7075 alloy is used in automobile and aerospace industry due to its high strength, toughness, and resistance against oxidation and corrosion [1]. Vehicle parts are usually exposed to erosion. Loss of original material from a solid surface with mechanical interaction between the surface and solid or liquid particle containing fluid is called erosion [2]. Researchers always try to find a way to reduce material loss and energy consumption [3]. Selection of proper material [4], processing techniques [5] and heat treatment $[6,7]$, effects the erosion resistance. Investigations and studies provide insight into the mechanisms of material removal during the wear process of material [8]. There are a number of methods to evaluate the erosion wear of materials using equipment, such as small feed rate erosion test equipment [9], particle jet erosion test equipment [10], coriolis erosion tester [11] and slinger erosion test equipment [12]. Solid particle erosion behavior of solutionized, artificially aged and annealed AA7075 alloy was investigated in this study. During tests, impingement angle, velocity and pressure were kept constant. $45^{\circ}$ impingement angle was used in experiments. Impingement velocity was $75 \mathrm{~m} / \mathrm{s}$ and air pressure was 3 bar. Garnet erodent particles used in experiments were 180 mesh. All these parameters were chosen to reach optimum erosion for ductile AA7075 metal [6-13].

\section{Experimental}

Cylindrical AA7075 samples with $40 \mathrm{~mm}$ diameter were used in experiments. The chemical composition of AA7075 is given in Table I.

${ }^{*}$ corresponding author; e-mail: erhan.balci@kocaeli.edu.tr
Chemical composition of the AA7075 alloy (wt\%).

\begin{tabular}{c|c|c|c|c|c}
\hline \hline $\mathrm{Zn}$ & $\mathrm{Mg}$ & $\mathrm{Cu}$ & $\mathrm{Si}$ & $\mathrm{Fe}$ & $\mathrm{Cr}$ \\
\hline 5.5 & 2.4 & 1.4 & 0.5 & 0.4 & 0.18
\end{tabular}

Samples were divided into three groups. All samples were solutionized at $470{ }^{\circ} \mathrm{C}$ for 2 hours and then water quenched. First group was left as solutionized. Second group was subjected to artificial aging heat treatment (T6) $120^{\circ} \mathrm{C}$ for 12 hours to obtain the highest hardness [14]. Third group was soaked at $410^{\circ} \mathrm{C}$ for 3 hours to achieve annealing after T6. Heat treatments were performed in an electronically controlled heat treatment furnace.

Erosion tests were performed in horizontal sand blasttype erosion test equipment. The test equipment is shown in Fig. 1. Garnet particles with the size of 180 mesh driven by a static air pressure of 3 bar, were accelerated along a $50 \mathrm{~mm}$ nozzle with a diameter of $5 \mathrm{~mm}$. The velocity of particles under 3 bar pressure was $75 \mathrm{~m} / \mathrm{s}$, measured by using double-disc method. All erosion experiments were run at particle impingement velocity of $75 \mathrm{~m} / \mathrm{s}$ and angle of impingement of $45^{\circ}$ (angle of highest achieved wear rates), by using 180 mesh garnet particles. Samples were cleaned by air blasting before and after erosion tests in order to remove sand and dust particles, and then samples were weighed on an electronic balance with an accuracy of $\pm 0.1 \mathrm{mg}$.

To characterize the morphology of eroded surfaces and in order to understand mechanism of material removal, eroded surfaces of samples were examined by using a scanning electron microscope Tescan Vega Sbu-II (Bruker EDS). 


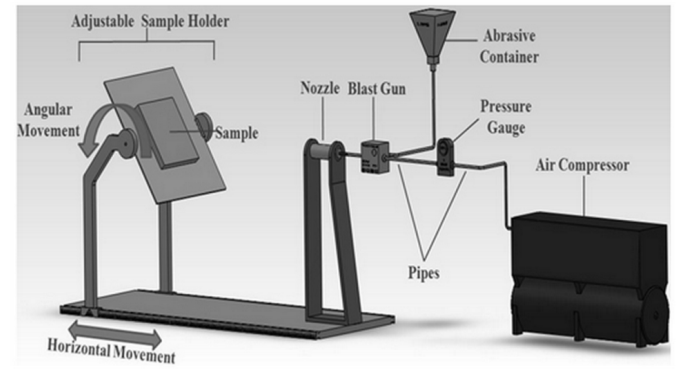

Fig. 1. Solid particle erosion test equipment.

\section{Results}

\subsection{Microstructure}

Elongated AA7075 grains are seen in Fig. 2. Elongation occurs in the extrusion direction. Light microscope view of solutionized AA7075 sample is given in Fig. 2a and SEM image of artificially aged AA7075 sample is given in Fig. 2b.
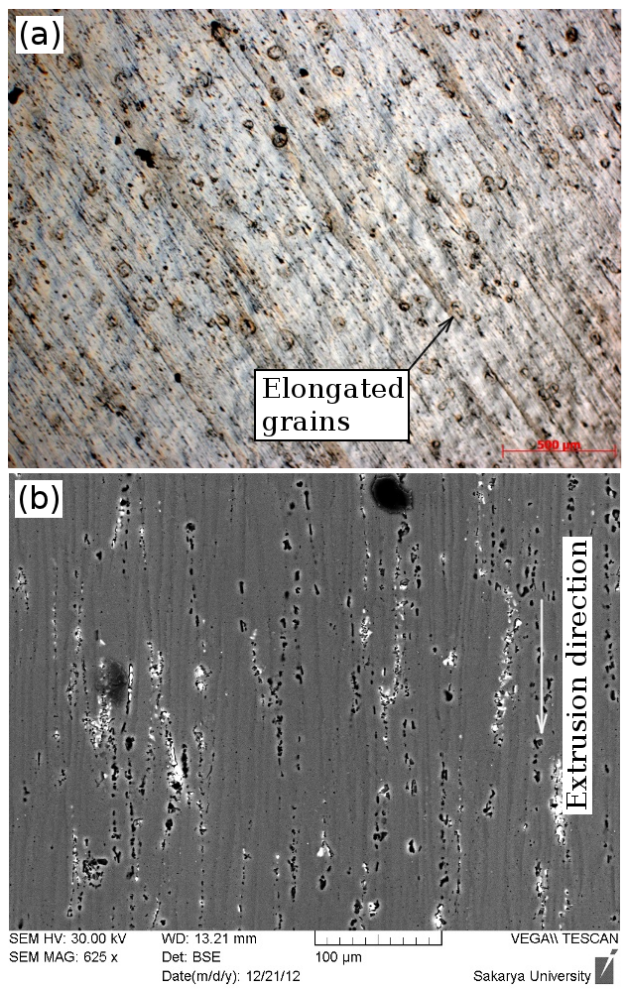

Fig. 2. (a) Light microscope view of solutionized AA7075, (b) SEM image of artificially aged AA7075.

The precipitation sequence of AA7075 is thought to be [15]: Supersaturated solid solution $\rightarrow$ GP Zones $\rightarrow \eta^{\prime} \rightarrow$ $\eta-\mathrm{MgZn}_{2}$.

In Fig. 3 the SEM image and EDS analysis results of artificially aged AA7075 sample are given. AA 7075 alloy includes $5.5 \%$ zinc and $2.4 \%$ magnesium. According to EDS results, there is $7.7 \%$ of $\mathrm{Zn}$ and $2.5 \% \mathrm{Mg}$ in point 2 . This shows, that in point 2 , there is a $\mathrm{MgZn}_{2}$ precipitate, which is compatible with the sequence above.

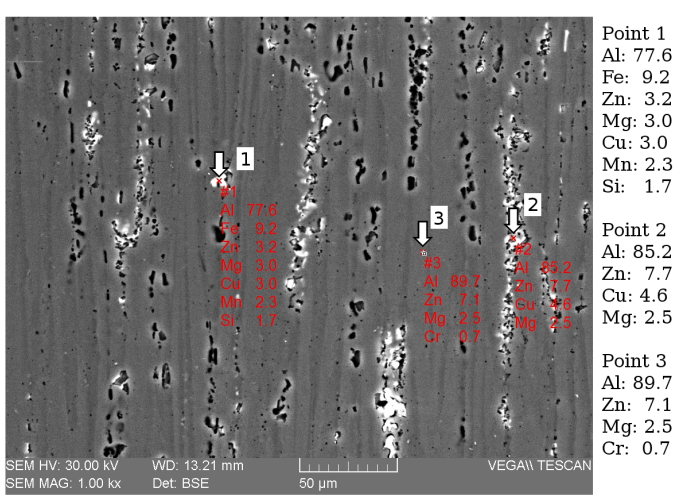

Fig. 3. EDS analysis of artificially aged AA7075 sample.

\subsection{Erosion rate}

Samples prepared at three different heat treatment conditions were exposed to erosive wear on the test equipment demonstrated in Fig. 1. Erosion test parameters and results of the experiments are shown in the Table II. The code numbers indicated in the first column of Table II define surfaces of samples, exposed to different heat treatment conditions. $\mathrm{S} 1_{f}$ means front surface of the square cross section for the sample prepared by solutionizing. Similarly $\mathrm{S}_{b}$ means back side of the solutionized sample of AA7075. Code numbers of $\mathrm{S} 2{ }_{f}$ and $\mathrm{S} 2{ }_{b}$ mean front side and back side of the samples that were artificially aged. The third sample coded as $\mathrm{S} 3_{f}$, $\mathrm{S} 3_{b}$ means front and back sides of the samples that were only solutionized. For comparison, a graphical representation of erosion rates and hardness of the different heat treated AA7075 samples, measured at constant erosion time, impingement angle and air pressure, is shown in Fig. 4.

Test results. Test parameters: erosion time TABLE II of $20 \mathrm{~s}$, impingement angle of $45^{\circ}$, pressure of 3 Bar, mesh 180, mass volume of $6.76 \mathrm{~g} / \mathrm{s}$.

\begin{tabular}{|c|c|c|c|c|c|c|}
\hline $\begin{array}{c}\text { Sam- } \\
\text { ple } \\
\text { Code } \\
\end{array}$ & $\begin{array}{c}\text { Hard- } \\
\text { ness } \\
{[\mathrm{HB}]}\end{array}$ & $\begin{array}{c}\text { Initial } \\
\text { weight } \\
{[\mathrm{g}]}\end{array}$ & \begin{tabular}{|c|} 
Final \\
weight \\
{$[\mathrm{g}]$} \\
\end{tabular} & $\begin{array}{c}\Delta m \\
{[\mathrm{mg}]}\end{array}$ & $\begin{array}{c}\Delta m_{\text {mean }} \\
{[\mathrm{mg}]}\end{array}$ & $\begin{array}{c}\text { Erosion } \\
\text { Rate } \\
{[\mathrm{mg} / \mathrm{g}] \times 10^{3}}\end{array}$ \\
\hline $\mathrm{S} 1_{f}$ & \multirow{2}{*}{85} & 23.37 & 23.34 & 27.7 & \multirow{2}{*}{27.80} & \multirow{2}{*}{205.62} \\
\hline $\mathrm{S} 1_{b}$ & & 23.34 & 23.32 & 27.9 & & \\
\hline$\overline{\mathrm{S} 22_{f}}$ & \multirow{2}{*}{142} & 23.79 & 23.76 & 29.5 & \multirow{2}{*}{29.50} & \multirow{2}{*}{218.20} \\
\hline $\mathrm{S} 2_{b}$ & & 23.76 & 23.73 & 29.5 & & \\
\hline $\mathrm{S} 3_{f}$ & \multirow{2}{*}{128} & 23.30 & 23.27 & 27.6 & \multirow{2}{*}{28.00} & \multirow{2}{*}{207.10} \\
\hline $\mathrm{S} 3_{b}$ & & 23.27 & 23.24 & 28.4 & & \\
\hline
\end{tabular}

\section{Conclusions}

Solutionized, precipitation hardened and annealed AA7075 samples were subjected to erosive wear. Parameters such as impingement angle, air pressure, particle mass flow and erosion time were kept constant. Following results were obtained: 


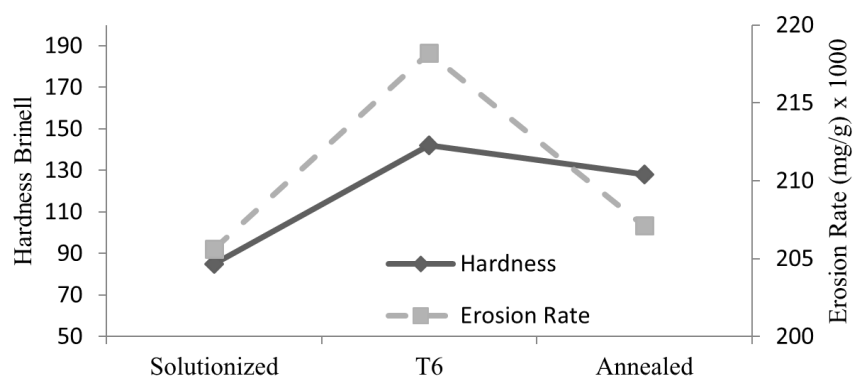

Fig. 4. Erosion rates and hardness values of samples.

- Erosion rate of AA7075 alloy increases as material gets harder. Hardening causes a rise in brittleness of the material. Thus the moving particles take chips from surface more easily and loss of material occurs.

- To avoid material loss against erosive particles, AA7075 should be used in ductile state. The highest ductility is obtained by solutionizing heat treatment.

- Wear mechanisms occurring at the different rated surfaces are cutting, impingement and removal of material from the surface of the specimen. Embedded erodent particles were not observed on the surfaces.

\section{Acknowledgments}

It is a pleasure to thank Egemen AVCU and Tamer SINMAZÇELIK for their help in the experimental part and KOU-BAP for financial support of this work.

\section{References}

[1] T. Burg, A. Crosky, Aeronautical Materials, University of New South Wales, 2001.

[2] Y.I. Oka, K. Okamura, T. Yoshida, Wear 259, 95 (2005).

[3] S. Karabay, Materials and Technology 48, 141 (2014).

[4] Y. Birol, E.A. Güven, L. Çapan, Materials Science and Technology 27, 1851 (2011).

[5] K. Prasad, S. Das, A.K. Jha, O.P. Modi, R. Dasgupta, A.H. Yegneswaran, Composites Part A 28, 301 (1997).

[6] A.K. Jha, A. Gachake, B.K. Prasad, R. Dasgupta, A.H. Yegneswaran, Journal of Materials Eng. and Performance 11, 37 (2002).

[7] K. Sanjay, D.P. Mondal, A.K. Jha, Journal of Materials Eng. and Performance 9, 649 (2002).

[8] T. Deng, M.S. Bingley, M.S.A. Bradley, S.R. De Silva, Wear 265, 945 (2008).

[9] W. Zhu, Z.Y. Mao, Proceeding of conference: Wear of Materials, ASME, 1987, p.787.

[10] R.G. Desale, K. Bhupendra, S.C. Gandhi, Wear 259, 196 (2005).

[11] H.M. Hawthorne, Y. Xie, S.K. Yick, Wear 255, 170 (2003).

[12] T. Deng, M.S. Bingley, M.S.A. Bradley, Wear 267, 2132 (2009).

[13] S. Fidan, E. Avcu, E. Karakulak, R. Yamanoglu, M. Zeren, T. Sinmazcelik, Materials Science and Technology 29, 1088 (2013).

[14] B. Sarıkan, E. Balcı, M. Übeyli, N. Camuşcu, Materials and Technology 46, 393 (2012).

[15] D.J. Lloyd, M.C. Chatuverdi, Journal of Materials Science 17, 1819 (1982). 